\title{
Research on the Development of Human Capital in Tianjin
}

\author{
Feng Han, Lin Zhu and Zheng Wang \\ College of Economics and Management, Tianjin Agricultural University, China
}

Keywords: rural human capital development; pertinence; effectiveness; rural revitalization.

\begin{abstract}
The development of rural human capital is the basis and premise of accelerating rural economic and social development, and the support and guarantee of Realizing Rural Revitalization Strategy and agricultural and rural modernization. In order to do a good job in the development of rural human capital, Tianjin has implemented a series of education and training activities and projects in recent years, and promulgated the local regulations on rural education and training in the country, which provides the legal system guarantee for the development of rural human capital in Tianjin. Based on the analysis of the data of the third national agricultural census in Tianjin, this paper obtains a large number of first-hand information by combining interviews with case studies, and understands the basic situation of human capital development in Tianjin. Through reviewing and comprehensive analysis of the practices of rural human capital development in Tianjin, this paper finds out the reference. The experience at home and abroad has put forward some measures and suggestions to strengthen the development of rural human capital and promote the Rural Revitalization in Tianjin.
\end{abstract}

\section{The Current Situation of Rural Human Capital Development in Tianjin}

In order to improve the pertinence and effectiveness of human capital development in rural areas, Tianjin Municipal Government has done a lot of work to improve the physical and mental health, ideological quality, knowledge quality and ability quality of rural residents, and has made remarkable achievements. Summarized below:

\subsection{Establish and Improve the Education and Training System}

From 2004 to 2007, Tianjin implemented the "351" training project, which trained 11.11 million rural labor force, including 221,000 people in Diploma education, 343,000 in agricultural vocational skills training, 483,000 in non-agricultural vocational skills training, 34,000 in rural brokers training, 29,000 in village cadres training from 2008 to 2012. Tianjin has launched a project to improve the quality of farmers, with 8976 teaching classes and a total investment of 246 million yuan, including 442 types of work or specialties, such as agricultural vocational skills, non-agricultural vocational skills, educational qualifications and so on. 538512 people participated in the training; 479,198 people have obtained corresponding certificates; 315,590 people have realized the transfer of employment and non-agricultural education. Employment rate is over $72 \%$. Since 2012, Tianjin has implemented a new type of vocational farmers training program, involving more than 30,000 trainees, such as graduates from colleges and secondary schools, returnees, veterans, and people in need of assistance in villages. Continuously provide technical support and guarantee for farmers, and strive to promote the rapid and sustainable development of rural economy and society by strengthening the development of rural human capital.

\subsection{Establish and Improve the Education and Training System}

Tianjin city farmers' education and training work is mainly responsible for the Rural Committee of Tianjin City, according to the occupation skill training work of farmers have a relatively complete training system. The city of three schools, namely: Tianjin rural cadres training center, training center and township enterprises in Tianjin city of Tianjin Agricultural Broadcasting School training institutions; farmers occupation skill training work level is mainly composed of four departments of agriculture agricultural area set up commitment are: Agricultural Machinery 
Agricultural Broadcasting School District, district School District, Center for the promotion of aquaculture technology and animal epidemic prevention and control of secondary heart; 2005 years to implement the "351" training project in Tianjin City, the municipal government to increase investment, in each township construction and improvement of the Township adult school culture total 162. Education in Tianjin city is mainly responsible for the Tianjin City Board of education, 14 adult colleges participate in farmers' education schools, 76 secondary schools and 26 higher occupation occupation school, and strive to meet the educational needs of different people. At present, the Tianjin Municipal Education Commission each year to undertake rural labor education and training 5000 people, completed by the radio and TV University, college, evening school, and 9 districts have training base and school culture, hoping to improve the Tianjin city farmers knowledge quality and the level of education, to strengthen rural manpower The purpose of capital development.

In addition, the practice teaching system of rural labor education and training in Tianjin is relatively perfect. With Haihe Education Park as the focus, Tianjin has built a number of national demonstration schools and characteristic specialties of Vocational education; Tianjin Public Vocational Skills Training Center, which is jointly invested by the Ministry of Education and the Tianjin Municipal Government, is the domestic leader and has a demonstration and leading role in Vocational Education in China. Each district has also built a public training base.

These farmer vocational skills training institutions have made great contributions to the economic and social development of rural areas in Tianjin, especially to the modernization of agricultural and rural areas.

\subsection{A Series of Laws and Regulations have been Formulated, and a More Perfect Organization and Management System for Education and Training has been Established}

In accordance with the actual needs of work, Tianjin ensures the legalization and standardization of the education and training of rural labor force. It has taken the lead in formulating the local laws and regulations on peasant education and training in Tianjin. The regulations stipulate that the leading organization is the administrative department of agriculture, which is the responsibility of the administrative department of agriculture. Responsible for overall planning, comprehensive coordination, supervision and management of peasant education and training work; financial guarantee stipulates that the municipal and agricultural district and county people's governments shall include peasant education and training funds in the annual financial budget, in which the peasant education and training funds shall be stored in the financial special account and earmarked for special purpose, and the peasant education and training funds shall be used to make the peasant education and training funds. The financial and agricultural administrative departments shall formulate the detailed rules for management. It makes Tianjin peasant education and training work in the forefront of the country, and plays a powerful role in promoting and guaranteeing the development of rural human capital.

\section{The Restrictive Factors of Rural Human Capital Development in Tianjin}

\subsection{Farmers' Cultural Knowledge base is Poor, and their Desire to Improve Their Educational Level and Skill level is Generally Low}

According to the data of Tianjin Third National Agricultural Census, 71\% of peasant households have below junior middle school education and $60 \%$ of village cadres have below junior middle school education. The cultural knowledge base of rural residents is relatively poor. Basic knowledge often determines the ability and interest of learning. The rural labor force generally has no strong willingness to receive education and training. In addition, some trained personnel are still unable to obtain employment after training, which seriously affects the enthusiasm of rural labor force in education and training, and brings great difficulties to the development of rural human capital. And the challenge. 


\subsection{Ways and Means to Improve Rural Human Capital need to be Studied and Improved}

Through investigation, we find that the ways and means of imparting knowledge and skills to farmers are often too single or even inconsistent with the cognitive characteristics and rules of the students, and the learning effect is not ideal; various education and training courses held are inappropriate due to the timing or inconvenient location of classes, which lead to farmers'inability to participate; and all places are improving. There are many attempts and successful experiences in the ways and methods of rural women's quality, but there is no systematic summary, development and promotion.

\subsection{The Teaching Implementation System is not Sound Enough, and its Function has not been Brought into full Play}

Through visiting and investigating, we find that there are four main problems in Tianjin rural labor force education and training system. First of all, the role of tertiary institutions has not been brought into full play. Education for academic qualifications in rural areas can not meet the needs of farmers, Tianjin Vocational Colleges and Universities in the training of farmers'skills also failed to play a full role; Secondly, vocational schools at all levels belong to different departments, each of which has its own way, and do not form a joint force, such as the existence of a single training specialty in agricultural and Guangzhou schools, radiation. Thirdly, due to the influence of the withdrawal of villages and towns and the reform of institutions, the adult culture training schools at the street and town levels have not been integrated in time and lack of funding sources, and the facilities need to be improved. Finally, some villages and rural enterprises lack school-running points. In addition, due to the lagging construction of teachers for employment training of rural labor force in Tianjin, the construction of teaching materials can not meet the needs of rural labor force and rural economic and social development; rural life security facilities need to be further strengthened and improved, and the way of life, production and entertainment of rural residents needs to be further guided. Education and promotion.

\subsection{The Basic Conditions for the Development of Rural Human Capital need to be Strengthened}

According to the survey of the training institutions and farmers, it is generally reflected that most of the training theoretical courses in Tianjin are on the high side, the practice courses are less, the number of theoretical courses and practical courses does not match; the training institutions are not complete and lack of professional training equipment; the training bases are fewer, and the training schools have more teachers. Unable to meet the requirements, especially in some private schools, there are fewer training bases. The training often relies on some public training bases, which results in different training effects and lack of effectiveness. The government has no funds to invest in village-level schools, and some village-level training schools need self-financing.

\section{Measures to Improve the Development of Rural Human Capital in Tianjin}

Based on the summary of the third national agricultural census and the survey of visits, combined with the practice of human capital development in rural areas of Tianjin, and drawing lessons from domestic and foreign practices and experiences in human capital development in rural areas, the following measures and suggestions are put forward to strengthen the development of human capital in rural areas of Tianjin.

\subsection{Adopt flexible and Diversified Methods of Human Capital Development to Improve the Effectiveness and Pertinence of Human Capital Development}

\subsubsection{Improving the rural Human Capital Development in Tianjin with the Demand Orientation}

In order to effectively enhance the effect of human capital development in rural areas, on the one hand, training management institutions at all levels should fully understand and analyze the 
employment needs of rural labor force in order to formulate training courses and contents that are suitable for the employment needs. The most important thing is to integrate the current situation and characteristics of local economic and social development and closely focus on the advantages. Potential characteristics and key industries to carry out education and training for the people. On the other hand, on the basis of a full understanding of the knowledge and skills of rural residents, we should adopt ways and means that are in line with their learning ability and cognitive characteristics. Through field investigation, we find that most of the rural labor force has a low level of education, blindness in choosing occupation, ignorance of how to train government organizations, what they should learn, and blindness in their training needs. Therefore, the government should strengthen research, propaganda and guidance to achieve education. Training and demand fully correspond to continuously improve the rural human capital development in Tianjin.

\subsubsection{Finding the Right Starting Point to fully Stimulate the Enthusiasm and Initiative of Rural Residents to Participate in Education and Training}

In view of the low enthusiasm and low initiative of farmers in learning knowledge and skills, we should find the right entry point to enhance the effectiveness of education and training. Firstly, education and training around the direction of economic and social development, the new demand generated by hot spots or the employment development direction and trend generated by new formats of business can easily arouse the enthusiasm and initiative of farmers to learn; secondly, training around the recruitment of enterprises and the adjustment of business operations of enterprises will receive better training. The third is around the rural economy and society, such as the key nodes of industrial and agricultural production and major events to carry out training, in order to stimulate their enthusiasm and initiative to receive education and training.

\subsection{Fully Tap and Bring into Play the Advantages of the Existing Legal System, so as to Speed Up the Development of Rural Human Capital}

In order to ensure the legalization and standardization of rural labor force education and training, Tianjin Municipal Government took the lead in formulating the local laws and regulations on peasant education and training in the whole country, the Regulations on Peasant Education and Training in Tianjin, which should be formulated in accordance with the relevant provisions of the Regulations and the planning requirements of Rural Revitalization strategy. Policy to speed up the development of human capital in rural areas.

\subsubsection{Establishing Rural Human Capital Development System based on Rural Revitalization Strategy}

In order to ensure the smooth implementation of Rural Revitalization Strategy in Tianjin and continuously improve the quality and level of human capital development, it is necessary to establish a complete system as a guarantee, closely around the strategic plan for Rural Revitalization formulated by the Party Central Committee and the State Council and the detailed rules for the implementation of Rural Revitalization Strategy formulated by the Tianjin Municipal Government, to provide human resources in rural areas. In the aspect of capital development, we should formulate management system, supervision and inspection system and financial funds management system to ensure the smooth implementation of rural human capital development in Tianjin. In addition, we should break the restriction of household registration, cover all the labor force working in rural areas of Tianjin with education and training objects, and bring more than 600,000 migrant workers into the scope of human capital development in rural areas of Tianjin, so as to ensure that the overall quality of human capital in rural areas of Tianjin is improved in an all-round way.

\subsubsection{Establishing an Organizational Management System with the Participation of Relevant Departments to form a Working Atmosphere of co Management}

With the orderly advancement of the reform of state institutions, Tianjin should also reduce the administrative levels according to the reform ideas at the national level, and lead the overall work of 
agriculture and rural areas by an administrative department. This can effectively overcome the confusion in the establishment of educational and training management institutions of rural labor force in Tianjin and greatly improve the management efficiency. The organizational management system, led by the Municipal Agricultural Commission and jointly participated by the Municipal Education Commission, Municipal Women's Federation, Municipal People's Social Bureau, League Municipal Committee and other relevant units, forms a working atmosphere of co-management.

\subsection{Innovating Rural Talent Management System and Promoting Rural Human Capital Development}

According to the Strategic Plan for Vitalization of Rural Areas (2018-2022), issued by the Central Committee and the State Council of the Communist Party of China, we should strengthen the support of talents for rural revitalization. We will implement a more active, open and effective talent policy to promote the rejuvenation of rural talents, so that all kinds of talents can do their best, show their talents and show their skills in the countryside.

\subsubsection{Innovating Talent Cultivation Mode, Creating More Local Talents}

We should innovate the training mode of rural professionals, make full use of the educational and training resources of all kinds of universities and vocational colleges at all levels, and train innovative and specialized talents for Rural Revitalization in cooperation with industry institutions, scientific research institutes, enterprises and institutions. We will support and train a number of agricultural professional managers, brokers, rural craftsmen, cultural talents and non-hereditary successors.

\subsubsection{Vigorously Cultivate New Professional Farmers}

Establish a comprehensive system of professional farmers, improve the supporting policy system; implement a new type of professional farmers training project; support new type of professional farmers to participate in secondary and higher agricultural vocational education through flexible schooling system; innovate training mechanism to support farmers'professional cooperatives, professional technical associations, leading enterprises and other main bodies to undertake training work; The pilot work of professional farmers' professional title assessment.

\subsection{Strengthen the Concept of Education and Training Institutions, Improve the Education and Training System}

\subsubsection{Strengthening the Integration and Construction of Education and Training Institutions}

Compared with other provinces and municipalities in China, Tianjin rural human capital development education and training institutions system is relatively complete, but due to the constraints of the management system, these schools are relatively scattered, or even single task, resulting in waste of resources. For example, the institutions involved in the cultivation of new-type professional farmers are under the jurisdiction of agricultural bureaus or service centers respectively. With the implementation of the reform of state institutions, these training institutions should also be under the direct leadership of the Agricultural Commission, integrating into a school, optimizing the allocation of resources, and operating efficiently. In addition, due to the particularity of agricultural production and the decentralization of farmers'residence, the focus of education and training of rural labor force should be subsided into villages or rural enterprises, focusing on the establishment and improvement of school-running points of village-level or rural enterprises, and striving to achieve "a little bit of a village" or "a little of an enterprise", which can greatly improve farmers' participation. The convenience and enthusiasm of education and training.

\subsubsection{Innovating the Concept of Teaching Staff Construction and Improving the Quality of Teachers Serving the "Three Rural Issues"}

It is the precondition for the development of human capital in rural areas to cultivate a team of teachers who are specialized and part-time, reasonable in structure, excellent in quality and competent in various kinds of knowledge and skills. Firstly, to establish a strict threshold for the 
qualification of teachers in peasant education and training, teachers should not only possess theoretical knowledge but also practical knowledge and teaching ability. Only after strict theoretical and practical assessment can they reach the qualified standards, can they be admitted. Secondly, the government should give appropriate financial support and cooperate with universities. Set up special courses to popularize new technologies and knowledge to teachers, so as to ensure that teachers'knowledge is closely linked with social development. Thirdly, we should establish a system of selection and employment of part-time teachers, especially practical instructors, and boldly select teachers from the front line of rural production management and service, so that on the one hand, a number of teachers can be selected. On the other hand, it can stimulate the enthusiasm of farmers to learn.

\section{References}

[1] Xinhua.Http://www.xinhuanet.com//politics/2015-09/28/c_128272780.htm General Secretary Xi Jinping's speech at the Global Women's summit

[2] Xinhua.Http://www.xinhuanet.com/2018-02/05/c_1122371920.htm.2018Central One document

[3] changfu Han . (2017). Vigorously implement the rural revitalization Strategy//Party's 19 major reports mentoring readings. Beijing: People's press, 2017:210-211.

[4] People's Daily society. (2018) Opinions of the State Council of the CPC Central Committee on the implementation of the strategy of rural revitalization. People's Daily, 2018-02-05 (01).

[5] People's Daily society. (2018) Central Rural Work conference held in Beijing. People's Daily, 2017-12-30 (01).

[6] Jinping $\mathrm{Xi}$. Win the victory and build a well-off society in an all-round way. Win the great victory of socialism with Chinese characteristics in the new era--Report at the 19th National Congress of the Communist Party of China [R]. Beijing: People's Publishing House. 2017:32.

[7] Yingchao Niu. Research on Environmental Pollution Control Models and Experiences of Western Market Economy Developed Countries. Journal of Chifeng College(Natural Science), 33, 64-66, (2017). 